\title{
Specialty Bed
}

National Cancer Institute

\section{Source}

National Cancer Institute. Specialty Bed. NCI Thesaurus. Code C50368.

A bed with a non-standard mattress, especially those for preventing or treating bed sores or for treatment of burn victims. 